\title{
PRODUÇÃO DE MUDAS CÍTRICAS NO RIO GRANDE DO SUL - DIAGNÓSTICO DA REGIÃO PRODUTORA ${ }^{1}$
}

\author{
PRODUCTION OF CITRIC SCION IN THE RIO GRANDE DO SUL STATE, \\ BRAZIL - DIAGNOSIS OF THE PRODUCING REGION
}

\author{
Gilmar Schäfer ${ }^{2}$ Ana Lúcia Cunha Dornelles ${ }^{3}$
}

RESUMO

Com o objetivo de caracterizar a produção de mudas cítricas, principalmente quanto ao uso de porta-enxertos e à origem do material propagativo utilizado, aplicou-se um questionário aos viveiristas da principal zona de produção de mudas do Estado do Rio Grande do Sul, pertencentes a duas associações de produtores de mudas do Vale do Rio Caí, a Avimuda e a Avimaffo. O questionário foi aplicado a um total de $35 \%$ dos viveiristas inscritos nas associações, sorteados ao acaso, durante os meses de maio a junho de 1998. Os principais resultados demonstram que a atividade de viveirista, nessa região, baseia-se, principalmente, na produção de mudas cítricas e já é desenvolvida há muitos anos; o porta-enxerto mais utilizado é o Poncirus trifoliata, sendo que a enxertia é realizada com borbulhas de origem não controlada.

Palavras-chave: produção de mudas, porta-enxertos, Poncirus trifoliata, Citrus, diagnóstico.

\section{SUMMARY}

A questionnaire was applied in the principal nursery citrus production área in Rio Grande do Sul State, Brasil, to characterize that área, in relation to rootstock and scion utilization. The nurseries researched belong to lhe 'Avimuda' and 'Avimaffo' producer associations $m$ the 'Caí' river valley. The questionnaire was applied to 35\% of the nurseries registered in the associations, from May to June 1998. The principal results show that the most used rootstock is the Peneiras trifoliata, and that the scion is obtained from material with non-controiled origin.

Key words: nursery production, rootstocks, Poncirus trifoliata, Citrus, diagnostic.

\section{INTRODUÇÃO}

O Brasil, dentro do contexto mundial, é o maior produtor de frutas cítricas, com uma produção que, segundo a FAO (1998), ultrapassa 23 milhões de toneladas. Desse montante, a produção principal é de laranjas, com predominância das cultivares Pêra, Natal e Valência, sendo em menor escala produzidas as laranjas 'Hamlin', 'Lima' e do tipo umbigo ('Bahia', 'Baianinha' e 'Monte Parnaso'). As tangerineiras também ocupam destaque na produção mundial - quarto lugar ( FAO, 1996), principalmente as cultivares 'Ponkan' e 'Murcote'. Pelo seu enorme cultivo em nível mundial, os citros desempenham um papel de acentuada importância sócioeconômica. No Brasil, estima-se que são cultivados mais de 2,2 milhões de hectares com cítricos, envolvendo mais de 400 mil empregos diretos, 20 mil citricultores e 17 indústrias de suco (MORAES et al., 1998).

O Brasil ocupa, atualmente, a primeira posição em produção e exportação de suco de laranja concentrado e congelado. A citricultura, apesar de inúmeras dificuldades, vem apresentando incremento considerável na área plantada, e as perspectivas futuras são promissoras, principalmente pela diversificação de mercados consumidores. O país possui condições edafoclimáticas favoráveis à citricultura, embora a maior produção verificada nos

\footnotetext{
${ }^{1}$ Parte da Dissertação de mestrado apresentada pelo primeiro autor à Faculdade de Agronomia, Universidade Federal do Rio Grande do Sul (UFRGS)

${ }^{2}$ Engenheiro Agrônomo, Aluno do Programa de Pós-Graduação da Faculdade de Agronomia da UFRGS. E-mail: schafer@vortex.ufrgs.br.

${ }^{3}$ Engenheiro Agrônomo, Doutor, Professor Adjunto, Departamento de Horticultura e Silvicultura, Faculdade de Agronomia, UFRGS, CP 776, 90001-970, Porto Alegre - RS. E-mail: alcunha@vortex.ufrgs.br. Autor para correspondência.
} 
últimos anos tenha sido causada unicamente pelo aumento da área plantada. Mas a produtividade é muito baixa, em comparação com a de outros países (RAMOS et al., 1997).

O Rio Grande do Sul apresenta um grande potencial para produção de cirros para o consumo in natura, por apresentar condições climáticas favoráveis para o desenvolvimento do fruto com características físico-químicas adequadas. Em termos económicos, a produção de frutos para consumo in natura é de grande importância, principalmente na Depressão Central do Estado, onde sua produção está localizada nas margens dos rios Caí e Taquari, cuja região é composta, em grande parte, por pequenas propriedades rurais (DORNELLES, 1991). Segundo JOÃO (1998), 50\% dos citros comercializados no Estado têm sido importados de outros estados, do Uruguai e até da Espanha.

A muda cítrica é o fator mais importante na formação de um pomar. $O$ caráter perene da cultura de citros coloca fundamental importância na escolha da muda, que é cultivada de 6 a 8 anos antes de revelar seu máximo potencial na produtividade e qualidade da fruta. Outros aspectos, como a longevidade do pomar, só serão reconhecidos em um intervalo ainda maior após o plantio. As características mais importantes da muda cítrica são a origem do enxerto e do porta-enxerto (plantas matrizes), e a qualidade do sistema radicular (LIMA, 1986).

Um dos fatores a se considerar é quanto à origem do material de enxertia utilizado pêlos viveiristas, pois segundo KOLLER (1994), os ramos ou garfos com as borbulhas devem ser retirados de plantas matrizes livres de vírus e outras moléstias transmissíveis pelas borbulhas. Por isso, as matrizes devem ser originárias de plantas básicas produzidas e mantidas por estações experimentais ou outras instituições credenciadas por órgãos oficiais fiscalizadores ou certificadores de mudas. Vários autores são unânimes ao afirmar que a utilização de material propagativo deve ser oriundo de matrizes de origem genética e sanidade comprovada (LIMA, 1986; GREVE et al., 1991; TEÓFILO SOBRINHO, 1991; KOLLER, 1994; PORTO et al., 1995; CARLOS, 1997).

Os porta-enxertos de plantas cítricas influenciam mais de 20 características hortícolas e patológicas da cultivar copa e seus frutos. Como resultado, o uso de porta-enxertos é considerado essencial na citricultura (CASTLE $\boldsymbol{e t}$ al., 1992).

Segundo MORAES et al. (1998), no Rio Grande do Sul, a maioria dos viveiristas registrados produzem mudas de bom aspecto, vigorosas, e que obedecem aos padrões legais visuais para comercialização. Porém, com certa frequência, as mudas apresentam problemas quanto à origem genética e à contaminação por viroses (exocorte, sorose e xiloporose). Com relação à origem genética, a mistura de variedades copa e porta-enxertos por parte dos viveiristas é bastante frequente. A venda de mudas contaminadas e as trocas de variedades copa e porta-enxertos, feitas pelo viveirista, criam sérios problemas ao citricultor, pois os pomares formados com essas mudas têm o rendimento e a longevidade comprometidos, além de causar transtornos na comercialização e na época de colheita.

Outro problema da produção de mudas no Rio Grande do Sul é a falta de diversificação de porta-enxertos, pois, segundo estimativas, mais de 90\% das mudas são enxertadas sobre Poncirus trifoliata (MORAES et al., 1998). Isso toma a citricultura vulnerável ao surgimento de moléstias que afetem esse porta-enxerto, como ocorreu com a 'Tristeza' dos citros na década de 40 (MOREIRA \& MOREIRA, 1991), ou com o 'Declínio' na década de 70 (BERETTA et al., 1989) provocando perdas consideráveis à citricultura nacional. Assim, este trabalho teve como objetivo caracterizar a produção de mudas cítricas, principalmente quanto ao uso de porta-enxertos e à origem do material propagativo utilizado.

\section{MATERIAL E MÉTODOS}

A caracterização da produção de mudas cítricas do Estado do Rio Grande do Sul foi realizada aplicando-se um questionário, durante os meses de maio a junho de 1998, aos integrantes de duas associações de produtores de mudas do Vale do Rio Caí, ou seja, a Avimuda (Associação dos Viveiristas de Mudas Diversas - Pareci Novo) e a Avimaffo (Associação dos Viveiristas de Mudas de Árvores Frutíferas, Florestais e Ornamentais - São Sebastião do Caí). Essas associações contam com aproximadamente 105 sócios, sendo que a grande maioria produz mudas cítricas.

A aplicação do questionário foi feita a um total de $35 \%$ dos viveiristas inscritos nas associações (37 questionários), sorteados ao acaso, dentro das principais cidades produtoras de mudas cítricas (Pareci Novo, São Sebastião do Caí, Montenegro, Harmonia e Capela de Santana).

O questionário continha perguntas diretas, que foram as seguintes: 1) Nome do viveirista; 2) Nome do Viveiro; 3) Início das atividades; 4) Associação pertencente; 5) Município; 6) Atividades desenvolvidas na propriedade; 7) Quem iniciou a atividade; 8) Possui assistência técnica? Qual; 9) principais espécies produzidas; 10) Quantidade de mudas cítricas produzidas para comércio em 1998; 
13) Altura de enxertia; 14) Tipo de muda produzida: haste única ou copa formada; 15) Tempo médio necessário para a formação de mudas: (meses); 16) Principais porta-enxertos utilizados na produção de mudas cítricas; 17) $\mathrm{Da}$ origem da semente (propriedade, proximidades. Centros de pesquisa, Compra mudas prontas de porta-enxertos e Outros); 18) Motivos da escolha dos porta-enxertos; 19) Local de retirada das borbulhas; 20) Tipo de enxertia realizada; e, 21) Controle fitossanitário, qual?

$$
\text { Para a análise dos }
$$

resultados, procedeu-se à analise exploratória dos dados segundo metodologia descrita por RIBOLDI (1993), utilizando a tabulação dos dados, para posterior análise de medidas de tendência central (média e moda) e distribuições de frequências.

\section{RESULTADOS E DISCUSSÃO}

Após a análise dos questionários respondidos, observou-se que, em relação ao item que abordava quem havia iniciado a atividade na propriedade, $53 \%$ indicaram que eles próprios haviam iniciado e o restante respondeu que a atividade foi herdada de familiares. O tempo de envolvimento nessa atividade (Figura 1) também realça essa relação, pois a grande maioria dos viveiristas está há mais de 20 anos trabalhando na atividade. Nota-se ainda que existem poucos iniciando a atividade (9\%) e uma quantidade razoável de viveiristas (12\%) com mais de 40 anos de atividade.

Outra questão levantada foi quanto às atividades desenvolvidas na propriedade, sendo que somente $20 \%$ dos proprietários têm como única fonte de renda o viveiro; os demais diversificam a propriedade com pomar (36\%), pecuária (19\%), produção de flores (11\%) - principalmente roseiras, produção de melancia (3\%) e outras atividades (11\%). Isso demonstra que a atividade pode estar se tomando secundária na propriedade ou que a renda está sendo complementada com outras atividades.

Em relação às principais espécies produzidas dentro do viveiro, observou-se que a grande maioria $(67 \%)$ produzem somente citros. Os demais trabalham com citros (como produção principal) e ainda roseiras (11\%), uvas e ameixeiras
(19\%) e árvores nativas (11\%). Segundo dados descritos por MORAES et al. (1998), os principais municípios produtores de laranjas encontram-se situados no vale do rio Caí, por isso a tradição na produção de mudas cítricas desta região.

Na tabela 1, é apresentada a percentagem de mudas cítricas produzidas para comércio em 1998. Em geral, as mudas produzidas destinam-se a plantios para comércio de frutos ira in notara; isso considerando que as tangerineiras, as laranjeiras doces e de umbigo, os limoeiros e parte das laranjeiras para suco chegam a valores superiores a $80 \%$. Isso é perfeitamente justificável, pois segundo os dados apresentados por JOÃO (1998) sobre importação de frutas frescas no Rio Grande do Sul, associados às condições climáticas favoráveis à citricultura, apresentada por DORNELLES (1991), o

Tabela 1 - Classificação percentual das mudas cítricas produzidas para comércio em 1998, na Região do Vale do Rio Caí, RS.

\begin{tabular}{lcc}
\hline Grupo & Variedade ou subgrupo & $\begin{array}{c}\text { Percentagem de mudas } \\
\text { produzidas }\end{array}$ \\
& Doces & 6,86 \\
Laranjeiras & Suco & 21,56 \\
& Umbigo & 20,58 \\
& Total & 49,00 \\
& 'Montenegrina' & 18,48 \\
& 'Cai' + 'Pareci' & 8,36 \\
Tangerineiras & 'Ponkan' & 7,92 \\
& 'Murcote' & 7,04 \\
& Outras & 2,20 \\
Limoeiros & Total & 44,00 \\
Outros & Total & 6,00 \\
& Total & 1,00 \\
\hline \multirow{2}{*}{ Total } & & \\
& & 100,00 \\
\hline
\end{tabular}


Estado possui um grande potencial para a produção de frutas destinadas ao mercado in natura. Dentre as laranjeiras doces, as mais produzidas são a 'Tardia' (nomenclatura usada pêlos viveiristas) e a Tiralima'. Para suco, a principal é a laranjeira 'Valência', em menor número 'Natal', 'Seleta', 'Tobias', entre outras. As laranjeiras de 'umbigo' mais produzidas são a 'Monte Parnaso', seguidas da 'Bahia' e 'Baianinha'. Em relação a limas ácidas e limoeiros, são produzidos em maior escala os cultivares 'Tahiti' e 'Siciliano'.

Em valores absolutos, a produção de mudas cítricas apontadas por esses viveiristas ultrapassa a 880 mil. Em 1996, segundo levantamento feito pelas Associações (SCHMITZ, J.A.K., 1996 - comunicação pessoal), a produção, no vale do rio Caí (São Sebastião do Caí, Pareci Novo, Montenegro, Capela de Santana, Harmonia e outros), ultrapassou a 1 milhão e 800 mil mudas, de um total de 128 produtores com média de 14.740 mudas por produtor.

O uso de porta-enxertos pêlos viveiristas é pouco diversificado. A grande maioria das mudas formadas $(97,53 \%)$ está enxertada em Poncirus trifoliata, 1,66\% das mudas com limão 'Cravo', $0,51 \%$ com laranja 'caipira' e $0,29 \%$ com citranges. Essa percentagem de plantas enxertadas sobre Poncirus trifoliata ainda não é maior por esta apresentar incompatibilidade com o tangoreiro 'Murcote' (CARLOS et al., 1997), forçando os viveiristas a usarem outros porta-enxertos. Esses dados dão suporte à preocupação dos técnicos ao se reportarem à vulnerabilidade genética que a cultura pode apresentar, na presença de uma nova moléstia que afete o porta-enxerto, como foi o caso da 'Tristeza' que, praticamente, dizimou a citricultura brasileira na década de 40 e, mais recentemente, o 'Declínio dos Citros', pois o Poncirus trifoliata é tido como suscetível a esse mal (CARLOS $\boldsymbol{e t}$ al., 1997).

Em relação à origem da semente, observou-se que $65 \%$ do material propagativo dos porta-enxertos (sementes) é oriundo da propriedade, sendo que alguns viveiristas as coletam em cercas vivas nas proximidades (17\%), compram mudas prontas $(7 \%)$, ou adquirem de outras formas (compra de sementes ou frutos dos porta-enxertos). Isso é determinado, principalmente, pelo fato do Poncirus trifoliata produzir frutos e sementes em grandes quantidades (560 frutos/caixa e 38 sementes/fruto CARLOS et al., 1997), diminuindo a área de cultivo e o número de frutos necessários. A compra de mudas prontas, normalmente produzidas em tubetes, tem o objetivo de reduzir ou retirar uma das etapas de formação das mudas de porta-enxerto.
Tabela 2 - Motivos alegados pelos viveiristas para a escolha do porta-enxerto, na Região do Vale do Rio Caí, RS.

\begin{tabular}{lc} 
Motivos alegados & Percentagem \\
\hline & 3 \\
Resistência à gomose & 3 \\
Fácil propagação & 6 \\
Adaptação a solos úmidos & 26 \\
Adaptação ao clima & 26 \\
Facilidade de trabalhar (manejo) & 29 \\
Preferência do consumidor & 43 \\
Desenvolvimento maior & 51 \\
Facilidade de obter material propagativo (semente) &
\end{tabular}

$\mathrm{Na}$ tabela 2, são apresentados os principais motivos alegados pêlos viveiristas para a escolha do porta-enxerto. Nota-se que o motivo que teve maiores indicações foi a facilidade de obter material básico (sementes) e também a preferência do consumidor. A preferência do consumidor ao Poncirus trifoliata normalmente está relacionada às boas características de fruto inferidas, tamanho de copa reduzida, o que facilita as condições de manejo da cultura, e resistência às principais moléstias (KOLLER, 1994; CARLOS et al., 1997).

Segundo a portaria do Ministério da Agricultura (Lei número 6.507 de 19 de dezembro de 1997, Decreto número 81.771 de 7 de junho de 1978 - PORTO et al., 1995) sobre os padrões mínimos de qualidade para mudas cítricas, a enxertia deve ser realizada entre 10 a $20 \mathrm{~cm}$ de altura a partir do colo da planta, e a muda não pode ter mais de 36 meses de formação desde a semeadura do portaenxerto. No resultado do questionário, notou-se que a enxertia foi realizada o mais baixo possível, mas mesmo assim os viveiristas $(77 \%)$ respeitavam a margem de $10-20 \mathrm{~cm}$; apenas $23 \%$ fazem a enxertia o mais alto possível $(20-30 \mathrm{~cm})$. O tempo de formação das mudas é de 36 meses para a maioria dos viveiristas: $\mathrm{o}$ primeiro ano para o desenvolvimento do porta-enxerto na sementeira, o segundo ano para o crescimento do porta-enxerto no viveiro, após a repicagem, e o último ano para o desenvolvimento do enxerto. Somente os que compram mudas de porta-enxerto desenvolvidas em casa de vegetação (tubetes) diminuíam esse período.

A figura 2 apresenta a distribuição do local da retirada das borbulhas. $O$ fato de que a grande maioria dos viveiristas retira o material de enxertia do pomar ou do próprio viveiro pode acarretar na produção de mudas contaminadas por vírus ou outras moléstias, que poderão manifestar os sintomas posteriormente no pomar. Isso vai contra o que é preconizado por LIMA (1986), GREVE $\boldsymbol{e t}$ al. 


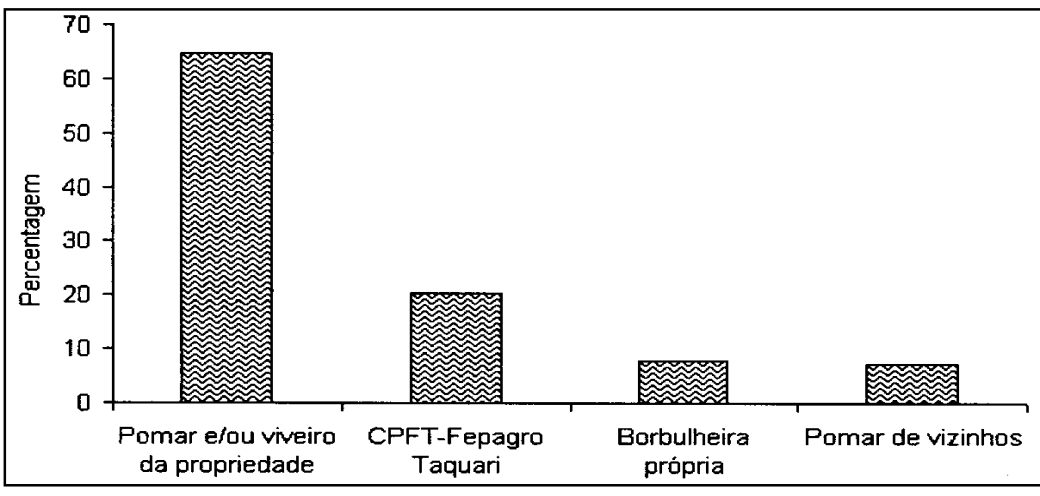

Figura 2 - Local de retirada das borbulhas pelos viveiristas.

(1991), TEÓFILO SOBRINHO (1991), KOLLER (1994), PORTO et al. (1995) e CARLOS (1997), os quais relatam que a utilização de material propagativo deve ser oriundo de matrizes de origem genética e sanidade comprovada. Também se deve ressaltar que a procura por borbulhas em centros de pesquisa, como o Centro de Pesquisa de Fruticultura de Taquari - Fepagro, nem sempre é atendida na sua totalidade, como foi descrito por SOUZA et al. (1998), o que limita o uso de material sadio.

Quanto aos tratamentos fitossanitários realizados, $43 \%$ dos viveiristas fazem aplicações regulares de fungicidas e controlam a gomose (Phytophtora sp.) com o uso de 'Fosetil Alumínio', 49\% fazem o controle de pulgões e cochonilhas e $100 \%$ controlam o 'minador das folhas' dos citros (Phyllocnistis citrella Stainton). O controle da gomose com 'Fosetil Alumínio' evita a manifestação da doença nas mudas por ação fungistática, mas não mata as formas de resistência (FEICHTENBERG, 1990). Como existe uma grande quantidade de viveiristas que fazem aplicações sistemáticas para o controle da gomose, eles deveriam esclarecer os compradores dessa prática. Quanto ao controle do 'minador das folhas' dos citros, nota-se que está associado à prevenção do cancro cítrico, pois, além de causar elevados danos em brotações novas, é porta de entrada para bactérias pelas lesões deixadas, preocupação já levantada por MORAES et al. (1998).

Todos os viveiristas entrevistados possuem responsável técnico. Em relação ao tipo de mudas, estas são predominantemente comercializadas em raiz nua, sendo que apenas para o comércio varejista elas são embaladas em sacos plásticos ou jacas. Considerando-se o destino, verificou-se que $64 \%$ da produção de mudas destinase a pomares comerciais. Observou-se também que
$99,5 \%$ das mudas são comercializadas com a copa formada.

\section{CONCLUSÕES}

Mais de $78 \%$ das mudas cítricas produzidas para venda em 1998, pêlos viveiristas consultados, são de cultivares para consumo in natura. Na região do Vale do Rio Caí, o porta-enxerto mais utilizado pêlos viveiristas é o Poncirus trifoliata. A origem das sementes dos porta-enxertos é basicamente da propriedade ou das proximidades. A enxertia é realizada com borbulhas de origem não controlada.

\section{AGRADECIMENTO}

Os autores agradecem às pessoas que tomaram possível este trabalho: Secretário da Agricultura de Pareci Novo, Engenheiro Agrónomo Edmundo H. Schmitz; Engenheiro Agrónomo Cristiano Limberger (Montenegro); Presidente da Avimaffo, Sr. José Walmir Wemer; Presidente da Avimuda, Engenheiro Agrónomo Mauri Hilgert.

\section{REFERÊNCIAS BIBLIOGRÁFICAS}

BERETTA, M.J.G., ROSSETI, V., TEIXEIRA, A.R.R., $\boldsymbol{e} \boldsymbol{t}$ al. Aplicação dos testes diagnósticos para declínio em plantas cítricas submetidas à transmissão por enxertia de aproximação de raízes. Laranja, Corderópolis, v.10, n.2, p.335-346,1989.

CARLOS, E.F., STUCHI, E.S., DONADIO, L.C. Porta-enxertos para a citricultura paulista. Jaboticabal : Funep, 1997. 42p.

CASTlE, W.S., TUCKER, D.P.H., KREZDORN, A.H., $\boldsymbol{e} \boldsymbol{t}$ al. Rootstocks. University of Florida. Disponível on line em: http:\www.hammock.ifas.ufl.edu. 1992.

DORNELLES, C.M.M. Citricultura do Rio Grande do Sul. h: RODRIGUES, O., VIÉGAS, F., POMPEU JÚNIOR, J., et al Citricultura brasileira. Campinas, SP : Fundação Cargill, 1991. v.1.p.38-41.

FAO. Oranges; tangerines, mandarins, clementines and satsuinas; lemons and limes, grapefruit and pumelos. Roma : Producuon yearbook, 1996. v. 50 e 52.

FAO. Oranges; tangerines, mandarins, clementines and satsumas; lemons and limes, grapefruit and pumelos. Roma : Production yearbook, 1998. v. 50 e 52.

FEICHTENBERG, E. Gomose de Phytophthora dos citros. Laranja, Corderópolis, v.11, n.1, p.97-122,1990.

GREVE, A., PRATES, H.S., MÜLlER, G.W. Produção de borbulhas certificadas de citros no Estado de São Paulo. In: RODRIGUES, O., VIÉGAS, F., POMPEU JÚNIOR, J., $\boldsymbol{e}$ a $\boldsymbol{a l}$. Citricultura brasileira. Campinas, SP : Fundação Cargill, 1991. v.1,p.302-317. 
JOÃO, P.L. Situação e perspecdva da citricultura no Rio Grande do Sul. In: REUNIÃO TÉCNICA DE FRUTICULTURA, 5, 1998, Veranópolis, RS. Anais... Veranóplis : FEPAGRO, 1998. p.15-18.

KOLLER, O.C. Citricultura: laranja, limão e tangerina. Porto Alegre : Rigel, 1994. 446p.

LIMA, J.E.O. de. Novas técnicas de produção de mudas cítricas. Laranja, Corderópolis, v.7, n.2, p.463-468, 1986.

MORAES, L.A.H., SALDANHA SOUZA, E.L. de, BRAUN, J., et al. Cadeia produtiva da laranja no Rio Grande do Sul. Porto Alegre : Fundação Estadual de Pesquisa Agropecuária Secretaria da Ciência e Tecnologia, 1998. 49p. Boletim Técnico FEPAGRO, 5

MOREIRA, C., MOREIRA, S. História da citricultura no Brasil. In: RODRIGUES, O., VIÉGAS, F., POMPEU JÚNIOR, J., et al Citricultura brasileira. Campinas, SP : Fundação Cargill.1991. v.1,p.1-21.

PORTO, O. de M., RECK, S.R., MORAES, L.A.H. de, $\boldsymbol{e t}$ al. Recomendações técnicas para a cultura de citros no Rio
Grande do Sul. Porto Alegre : Fundação Estadual de Pesquisa Agropecuária - Secretaria da Ciência e Tecnologia, 1995. 78p. Boletim Técnico FEPAGRO, 3.

RAMOS, J.D., PASQUAL, M., RIBEIRO, V.G., et al. Obtenção de porta-enxertos intergenéricos em citros. Pesquisa Agropecuária Brasileira. Brasília, v.32, n.10, p.1047-1051, 1997.

RIBOLDI, J. Elementos básicos de estatística. Série B: Trabalho de apoio didático. Porto Alegre : Universidade Federal do Rio Grande do Sul, Instituto de Matemática e Estatística: Cadernos de Matemática e estatística, 1993. 61 p.

SOUZA, E.L.S., MORAES, L.A.H. de, BECKER, R.F.P., et al. Resultados preliminares das cadeias produtivas de citros no Rio Grande do Sul. m: REUNIÃO TÉCNICA DE FRUTICULTURA, 5, 1998, Veranópolis, RS. Anais... Veranóplis : FEPAGRO, 1998. p.102-109.

TEÓFILO SOBRINHO, J. Propagação dos citros. $\mathrm{h}$ RODRIGUES, O., VIÉGAS, F., POMPEU JÚNIOR, J., et al. Citricultura brasileira. Campinas, SP : Fundação Cargill, 1991. v.1,p.281-301.

Ciência Rural, v. 30, n. 4, 2000. 